\title{
Experience in Engineers Training on Multiple Integrals in the Nomotex DLS
}

\author{
Yury I. Dimitrienko ${ }^{1 *}$, Michael P. Gordin ${ }^{1}$, Elena A. Gubareva ${ }^{1}$, Julia V. Zakharova ${ }^{1}$, \\ Oksana V. Skudneva ${ }^{1}$, Anna E. Pichugina ${ }^{1}$, and Natalya E. Trishina ${ }^{1}$ \\ ${ }^{1}$ Bauman Moscow State Technical University, 2nd Baumanskaya str., 5/1, 105005, Moscow, Russia
}

\begin{abstract}
The paper discusses a new approach to teaching the discipline "Multiple and curvilinear integrals, series" for engineers, using a new digital information and educational environment "NOMOTEX", developed at the Department of Computational Mathematics and Mathematical Physics, Bauman Moscow State Technical University. A new methodology for conducting lectures and practical classes for the Multiple Integrals course using Nomotex DLS is presented. The article analysed to the experience of training engineers at the Bauman Moscow State Technical University course on Multiple Integrals, including the advantages of learning using interactive computer visualization of mathematical concepts.
\end{abstract}

\section{Introduction}

Education in any country follows centuries-old traditions - it is enough to remember that the system of lecturing took shape in the Middle Ages, and to this day, world universities use a centuries-old, well-established way of organizing their departments and the names of employees' positions. Therefore, although education needs to keep up with the times, preparing cadres for science and competitive industry, it is important to do it carefully and delicately, without destroying what is respectfully called School and traditions.

It is under the slogan "do no harm" that the Department of Computational Mathematics and Mathematical Physics (FS-11) of the Bauman Moscow State Technical University (BMSTU) in 2015 began to create the digital educational system NOMOTEX. The initiators of the development of the NOMOTEX concept - professor Dimitrienko Yu.I. and associated professor Gubareva E.A., having analyzed the existing advanced trends in digital education, created a new concept of mathematical learning based on the neural network representation of mathematical knowledge, and also proposed basic approaches to creating a new generation of e-courses based on a single hierarchical knowledge base [1-2]. In addition, it was possible to create a team of like-minded people from their colleagues, including students, graduate students and young teachers, programmers, formulating goals and objectives for each participant.

As a result of hard work, by the end of 2016, the first edition of the digital information and educational platform NOMOTEX was developed, which included the first 2 electronic

*Corresponding author: dimit@bmstu.ru 
courses - Mathematical Analysis (1 semester) and Analytical Geometry [3]. Later DLS Nomotex began to dynamically develop and include new mathematical sections - the "Electronic Knowledge Tree" began to grow, growing with new shoots and branches. At the moment, DLS Nomotex includes 13 electronic courses in all the main sections of the basic mathematical education of engineers - "Analytical geometry", "Mathematical analysis", "Multiple and curvilinear integrals, series", "Ordinary differential equations", "Probability theory", "Integrals and differential equations", "Linear algebra and functions of many variables", "Theory of functions of a complex variable" and others.

Currently, there are many teaching materials in the classical mathematical disciplines. The works [4-9] present various modern approaches to modifying mathematical courses using modern technologies in education. However, these approaches consider e-courses as independent, unconnected into a single logical system.

In recent years, BMSTU has created a lot of educational and methodological literature, which can be read in electronic form without leaving home, connecting to the University library (elibrary.bmstu.ru) or using the platform of the Publishing House of the Bauman Moscow State Technical University (ebooks.bmstu.ru). However, students do not always know about the existence of certain manuals, they cannot systematize the network of knowledge on their own, they cannot switch to other designations using various sources of information.

The NOMOTEX system allows you to acquire all the necessary knowledge without losing sight of anything. The environment is based on Web technology, which allows it to be used even with a mobile phone. The teachers of the department who create courses in NOMOTEX include their most interesting developments in them.

\section{Methodical structure of the course "Multiple and curvilinear integrals, series" in The Nomotex DLS}

The academic discipline "Multiple and Curvilinear Integrals, Series" (MCIS) is read by the Department of FS-11 "Computational Mathematics and Mathematical Physics" of the Bauman Moscow State Technical University for bachelors studying in the direction of training 02.03.01 "Mathematics and Computer Science" and for engineers of a large number of areas of training.

MCIS is a basic math course usually taught in 2nd year in the fall semester. Since 2019, training in the MCIS course at the faculties of «Power Engineering», «Aerospace», «Rocket and Space Technology», as well as at the Department of FS-11 BMSTU is carried out using the NOMOTEX DLS developed at the Department of FS-11 [7, 8].

The methodological structure of the MCIS e-course in NOMOTEX DLS includes the following:

- Lectures;

- Seminars;

- Independent work;

- Homework;

- Midterm controls;

- Control works;

- Interim certification (exam).

\subsection{Methodology and technology of reading lectures}

The course of lectures on the MCIS discipline at in the NOMOTEX DLS is built in the form of a hierarchical neural network model and is structurally divided into 10 chapters: 
1. Jordan measure,

2.Double integral,

3. Triple integral,

4. Improper multiple integrals,

5. Curvilinear integrals,

6.Surface integrals,

7.Scalar field,

8.Vector field,

9.Numeric rows,

10. Functional rows,

11 Fourier series

12. Series in orthogonal systems.

Chapters 1-6 constitute Module № 1 and Chapters 7-12 constitute Module № 2 of the MCIS course.

Each chapter is divided into paragraphs, and the paragraphs consist of quanta of knowledge (axioms, definitions, theorems, etc.). All mathematical concepts inside the quantum are provided with hyperlinks, therefore there is a connection between the previously passed disciplines (mathematical analysis, analytical geometry, linear algebra, theory of functions of many variables). Knowledge (terms, mathematical concepts) is no longer «static», but is presented in «dynamics». A student who is studying a new mathematical concept can build his own graph - «the individual trajectory of the studied mathematical concept», which characterizes the connections between various mathematical concepts (parallel connections, as well as previous connections, that is, concepts that are the basis for the studied concept, while the depth of this trajectory is individual, depending on the knowledge of the student. This ensures continuity between courses, and also allows students to independently view the information they need online.

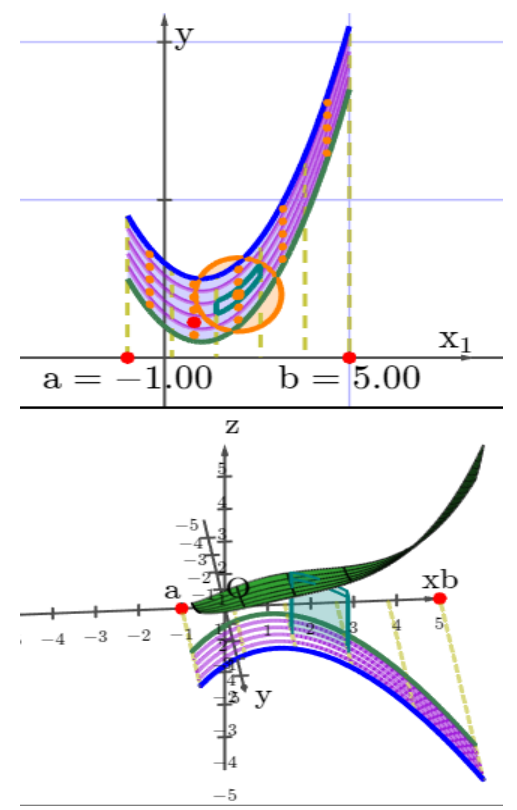

(a)

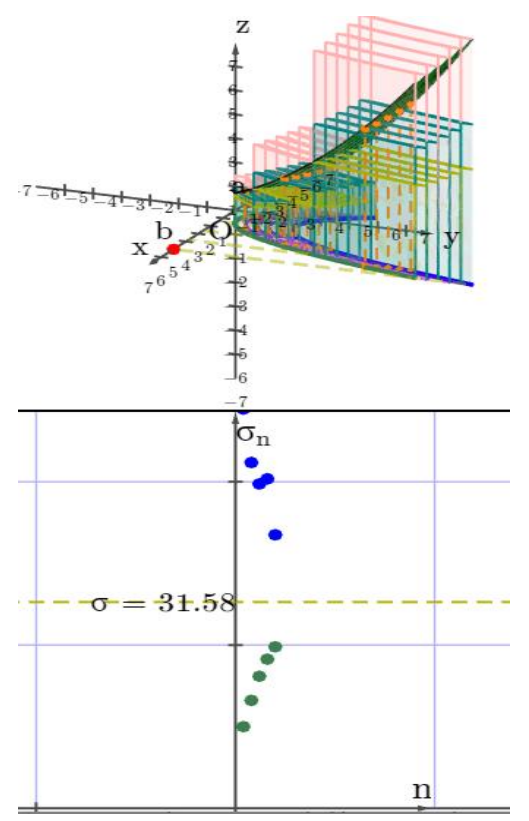

(b)

Fig.1. Visualization in the Nomotex DLS: (a) visualization of the definition "Integral sum"; (b) visualization of the proof of the theorem "Darboux's theorem". 
Much attention in the preparation of lectures is paid to the graphic presentation and animation of not only the basic definitions, but also the proofs of theorems (Fig. 1), which greatly increases the level of understanding of the mathematical foundations of the discipline. The graphic presentation of concepts is not just visualization, but this is a microcourse work, namely, using these examples, the student learns to independently analyze the ongoing process in the example, consider this process from different angles, change the parameters, watch the result, draw conclusions. In addition, the visualization of mathematical examples and engineering examples uses two sensory systems for perceiving information from 4 existing systems: visual and digital, which has a positive effect on the development of knowledge in the learning process.

Table 1 presents fragmentary statistics on how students view examples of all specialties and areas of training, where courses are taught "Multiple and Curvilinear Integrals" (or their variation with a different name) of different depth and breadth of content (Fig. 1). An analysis of statistics shows that the greatest number of views is among the groups for which these theorems are included in the exam program, for example, in groups E4-31, FS11-33B (FS11-33B are bachelors of the direction of training "Mathematics and Computer Science"). The smallest number of views is for groups for which this material is optional, for example, AS2-31, E8-31B groups.

It can also be noted that older students (for example, groups AS4-41, AS1-41) return to these theorems, who took this material optional, and it was not taken out for the exam, but with further training they needed it. The statistics also included first-year students who, starting to get acquainted with the system, look at these examples, for example, the FS1121B group (FS11-21B are bachelors of the direction of training "Mathematics and Computer Science"). This analysis allows us to conclude that it is necessary to expand the program of mathematical training for those engineers who have the above topics in the MCIS course as an option facultative.

Table 1. Fragmentary statistics.

\begin{tabular}{|c|c|c|c|}
\hline $\begin{array}{c}\text { Fig.1. (a) Visualization of the definition } \\
\text { "Integral sum" in The } \\
\text { Nomotex DLS }\end{array}$ & $\begin{array}{c}\text { Fig. 1. (b) Visualization of the proof } \\
\text { of the theorem "Darboux's theorem" } \\
\text { in The Nomotex DLS }\end{array}$ \\
\hline group & number of views & group & number of views \\
\hline AS4-41 & 13 & AS2-42 & 3 \\
\hline AS2-42 & 4 & FS11-41B & 3 \\
\hline FS11-41B & 2 & AS1-41 & 4 \\
\hline AS1-41 & 10 & FS11-42B & 2 \\
\hline FS11-42B & 1 & E7-41 & 1 \\
\hline E7-41 & 3 & AS2-32 & 6 \\
\hline AS3-41B & 1 & AS3-31B & 12 \\
\hline E4-31 & 29 & AS4-31 & 4 \\
\hline E7-31 & 21 & FS11-31B & 10 \\
\hline E8-31B & 1 & FS11-32B & 20 \\
\hline E9-31B & 8 & FS11-33B & 14 \\
\hline E9-32B & 9 & E1-31 & 3 \\
\hline AS1-31 & 13 & E1-32 & 3 \\
\hline AS2-31 & 5 & E1-33 & 5 \\
\hline AS2-32 & 8 & E3-39 & 1 \\
\hline AS3-31B & 6 & E4-31B & 1 \\
\hline AS4-31 & 28 & E6-32B & 1 \\
\hline FS11-21B & 13 & E8-31 & 1 \\
\hline FS11-32B & 18 & AS2-11 & 3 \\
\hline FS11-33B & 23 & & 4 \\
\hline
\end{tabular}


The classroom lecturing technology at the NOMOTEX DLS is based on the use of an interactive whiteboard. When conducting classroom lectures, students write in their workbooks only part of the information that appears on the interactive screen: basic concepts, theorem formulations. The rest of the lecture, students finish writing and working at home in their workbooks. Thus, the focus of the lecture in the audience is shifted not to the note taking of the lecture, but to the analysis and understanding of the topic in the classroom or on-line. Access to the Nomotex DLS for students and teachers is carried out by a personal login and password, which are given to everyone at the beginning of the semester by administrators.

To conduct distance classes, the NOMOTEX DLS has a subsystem "Video-conference", which allows lectures to be conducted remotely, including recording and uploading video clips in the NOMOTEX DLS system itself. In this case, students have the opportunity to repeatedly view video lectures, and also take notes in their workbooks.

\subsection{Methodology and technology of conducting seminars}

All tasks in practical classes in the Nomotex DLS are divided into topics, for each topic, basic theoretical information is briefly given. All examples are divided by difficulty level and given with a solution. A graphical representation of the problem is not given in all problems, so that the student can independently figure out the example. The teacher examines one example on the blackboard, shows the course and logic of solving the problem, then students solve the problems independently, either on the blackboard or in notebooks.

\subsection{Methodology and technology of independent work}

For independent work (IW) of the student, homework (according to options) and tasks for independent solution are provided, which are also introduced in the Nomotex DLS. They enter their answers into the program window, and then an automated check of the results is carried out in the Nomotex DLS. All results of all tasks and attempts to complete them are recorded in the student's Digital Trace subsystem.

\subsection{Methodology and technology of midterm control}

To control the development of knowledge, students perform midterm control (MC), which is a set of tickets, consisting of a practical and theoretical part. In the practical part, the student solves problems and enters the answer into the problem window. The theoretical one consists of tests: multiple choice questions, from which you need to choose the correct one.

Students perform milestone tests by receiving a ticket from the teacher through the Personal Account - which practically excludes the possibility of writing off from a friend, since the tickets are formed by the system itself and the possibility of repeated tickets is excluded.

To receive a MC ticket, a student enters his personal account, where a ticket is displayed, which is automatically generated by the system before the start of the test. Answers to any problems (MC, homework, IW or seminar assignments) can be complex expressions, which excludes the possibility of cheating or "guessing" the answer. For examples involving the input of complex mathematical expressions in the Nomotex DLS, there is a "Help Assistant" on how to enter symbolic and numeric answers. 


\section{Learning outcomes}

All results of independent work and midterm tests of the student are displayed in the teacher's personal account. In addition, for each module, a student's rating in points is automatically set, according to the work program of the MCIS discipline.

For prompt correction of detected typos, getting help, as well as generating suggestions for improving the content, DLS «Nomotex» created a feedback system with DLS «Nomotex» users. Students notice typos, or errors in tasks, point to them, and, thereby, also participate in the work and contribute to the creation of the course

\section{Conclusions}

The MCIS e-course has been developed, which is an integral part of the general system of the mathematical neural network of knowledge the Nomotex DLS. The MCIS e-course course contains all the lecture material, practical material and assignments for independent work, as well as assignments for control activities for the course. All types of tasks and control activities are performed electronically, on a computer or smartphone, and are checked automatically.

Due to the clear structure of the Nomotex DLS and the implementation of a new teaching technology, the possibility of a deeper and more visual study of the MCIS course is increased compared to traditional training. The teacher's work on checking the tasks of the current control becomes easier, the objectivity of the assessment increases, which is noted by the students.

\section{References}

1. Yu.I. Dimitrienko, E.A. Gubareva, A new technology for the mathematical training of engineering personnel based on a neural network model of knowledge, Innovations in Education, No. 11, pp.129-140 (2017)

2. Yu.I. Dimitrienko, E.A. Gubareva, Hierarchical neural network model for mathematical knowledge and software NOMOTEX for mathematical training of engineers, IOP Journal of Physics: Conference Series, volume 1141012010 , DOI:10.1088/1742-6596/1141/1/012010 (2018)

3. Yu.I. Dimitrienko, E.A. Gubareva, T.V. Oblakova, A.A.Prozorovskiy, Primeneniye tsifrovoy obrazovatel'noy credy NOMOTEX dlya obucheniya inzhenerov po kursu «Analiticheskaya geometriya», Dnevnik nauki, № 10 (22), pp. 7-15 (2018)

4. Ye. K. Khenner, Vysokorazvitaya informatsionno-obrazovatel'naya sreda vuza kak usloviye reformirovaniya obrazovaniya, Obrazovaniye i nauka, № 1 (110), pp.54-72 (2014)

5. V.I. Mayorova, D.A. Grishko, V.V Leonov, «Vivid mathematics» as a general vector of multidisciplinary STEM education for future aerospace engineers Acta Astronautica, 178, pp. 72-80, DOI: 10.1016/j.actaastro.2020.09.003 (2021)

6. N.A.a Serdyukova, V.I.b Serdyukov, Smart System Sustainability and Smart System Management (to be published) Intelligent Systems Reference Library, 191, pp. 157172, DOI: 10.1007/978-3-030-54470-6_9 (2021)

7. E.V. Lyapuntsova, I.M. Belozerova, V.G. Borkovskaya, I.I. Drozdova, Y.S. Baranova, Organization and Management of Educational Work in Universities in the Light of National Strategic Guidelines for the Development of Education, IOP 
Conference Series: Earth and Environmental Science, 459 (6), № 062031, DOI: 10.1088/1755-1315/459/6/062031 (2020)

8. E.V. Panfilova, E.N. Galaganova, Neural Network modeling of Thin Films Deposition Processes in the Master's Degree Programs electronics and Nanoelectronics and nanoengineerig , IOP Conference Series: Materials Science and Engineering, 781 (1), № 012016, DOI: 10.1088/1757-899X/781/1/012016 (2020)

9. V.A. Shakhnov, A.A. Glushko, E.V. Rezchikova, L.A. Zinchenko, V.V. Terekhov, V.V. Makarchuk, TCAD and Cognitive Visualization in Electronic Engineering Education : BMSTU Case Study 2020 5th International Conference on Information Technologies in Engineering Education, Inforino 2020 - Proceedings, № 9111802, DOI: 10.1109/Inforino48376.2020.9111802 (2020) 